\title{
Characterization of the myocardium in the 4-chamber view using accelerated free-breathing diffusion tensor MRI
}

\author{
Choukri Mekkaoui $^{1 *}$, Timothy G Reese ${ }^{1}$, Himanshu Bhat ${ }^{3}$, Marcel P Jackowski ${ }^{2}$, David E Sosnovik ${ }^{1}$ \\ From 19th Annual SCMR Scientific Sessions \\ Los Angeles, CA, USA. 27-30 January 2016
}

\section{Background}

Diffusion Tensor MRI (DTI) of the heart in vivo has conventionally been performed in the short-axis of the left ventricle (LV) [1]. While this allows all three coronary territories to be seen, the short-axis acquisition orientation has some limitations. Full coverage of the LV in the short-axis requires roughly 12 to 15 slices, and accurate evaluation of the apex of the heart is often compromised. In addition, a nominal slice thickness of 8 $\mathrm{mm}$ is routinely used. An accelerated free-breathing DTI acquisition of the heart in its horizontal long-axis (4-chamber view) would require fewer slices (6), reduce acquisition time, and improve the characterization of the anterior and apical walls. A 4-chamber view, previously not performed, may be particularly useful when studying the remodeling of these regions.

\section{Methods}

DTI was performed in healthy volunteers $(\mathrm{n}=7)$ on a clinical 3T scanner (Siemens Skyra), with an ECG-gated STE sequence. Acquisition parameters were: $\mathrm{FOV}=360 \times 200$ $\mathrm{mm}^{2}$, resolution $2.5 \times 2.5 \mathrm{~mm}^{2}$, thickness $=8 \mathrm{~mm}$, inplane GRAPPA rate $2, \mathrm{TE}=34 \mathrm{~ms}$, b-values $=0$ and 500 $\mathrm{s} / \mathrm{mm}^{2}, 10$ diffusion-encoding directions, 8 averages, and 12 contiguous short-axis and 6 contiguous 4-chamber slices. Rate 2 SMS excitation was followed by a blippedCAIPI readout. A sequential acquisition of diffusionencoding directions evenly distributes the rejections across all directions ensuring that we can select enough samples of each direction. STR was applied to reduce the misregistration resulting from respiratory motion [2]. Following STR, we utilize a novel entropy-based retrospective image

${ }^{1}$ Harvard Medical School - Massachusetts General Hospital, Charlestown, MA, USA

Full list of author information is available at the end of the article selection method to reject corrupted images and maximize SNR. Mean diffusivity (MD), fractional anisotropy (FA) and helix angle (HA) values were compared between breath-hold and free-breathing.

\section{Results}

Accelerated free-breathing DTI acquisition of the heart could be successfully performed in the 4-chamber view. Similar HA maps and tractograms were produced from the short-axis and 4-chamber acquisitions of the LV (Figures 1A-D). There was no statistical difference in HA, MD, or FA values between short-axis and 4-chamber acquisitions of the LV (Figures 1E-G). The 4-chamber view enabled the antero-apex and true apex to be better characterized, and suggested a reduction in the number of circumferential fibers at the true apex, in addition to the two-fold reduction in total scan time.

\section{Conclusions}

Accelerated free-breathing DTI of the human heart can be accurately performed in the 4-chamber view. This capability may be valuable in characterizing remodeling in the anterior and apical walls. Imaging the myocardium in the 4-chamber view significantly reduces scan time compared to the conventional short-axis view, which could facilitate the clinical translation of cardiac DTI.

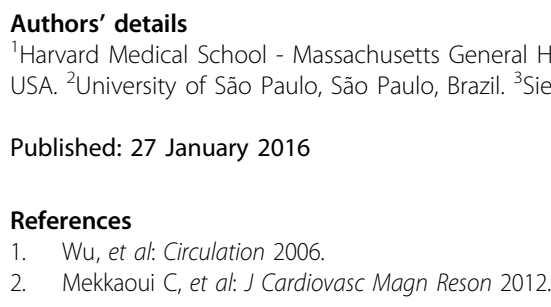




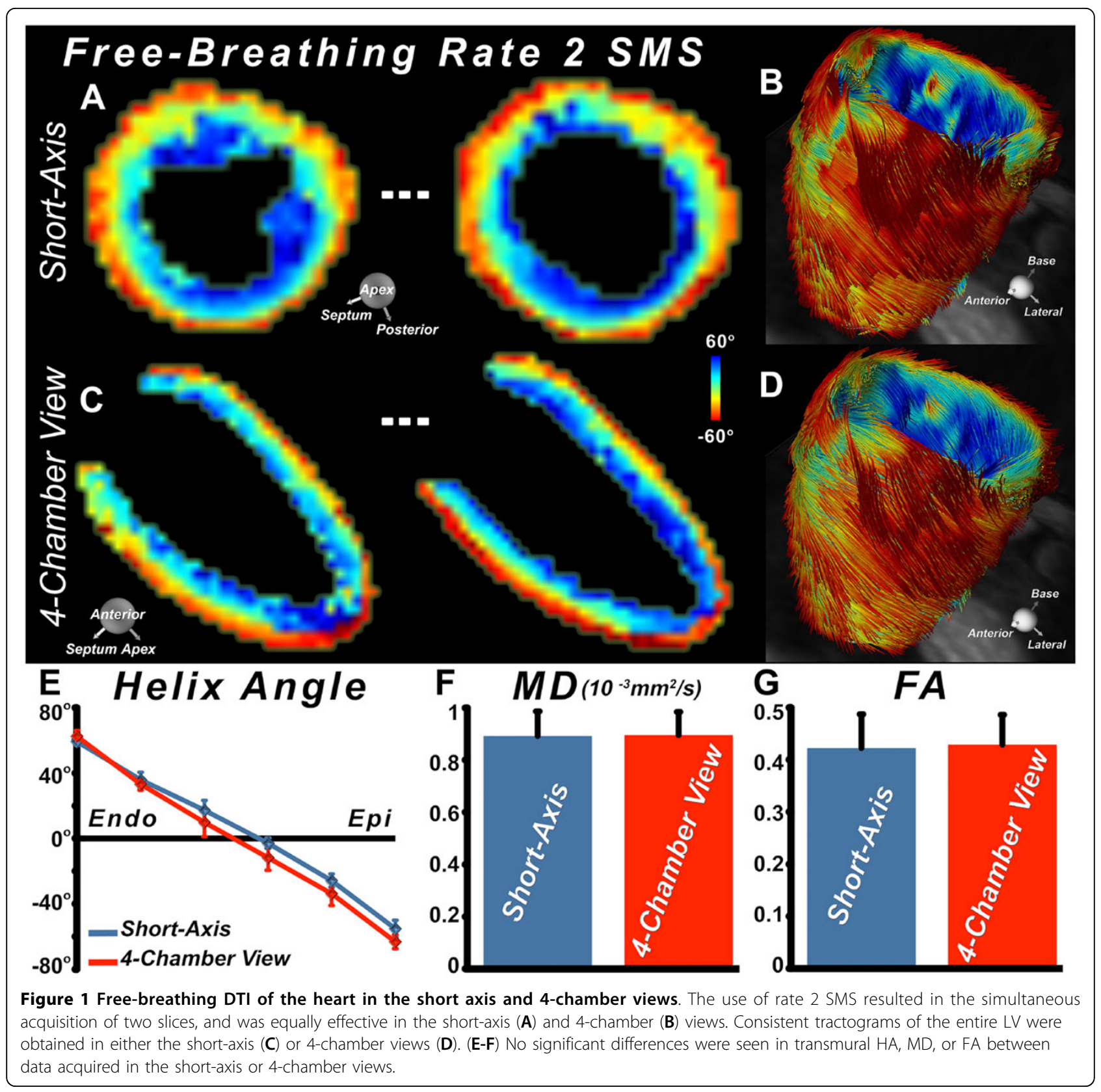

doi:10.1186/1532-429X-18-S1-P13

Cite this article as: Mekkaoui et al:: Characterization of the myocardium in the 4-chamber view using accelerated free-breathing diffusion tensor MRI. Journal of Cardiovascular Magnetic Resonance 2016 18(Suppl 1):P13.
Submit your next manuscript to BioMed Central and take full advantage of:

- Convenient online submission

- Thorough peer review

- No space constraints or color figure charges

- Immediate publication on acceptance

- Inclusion in PubMed, CAS, Scopus and Google Scholar

- Research which is freely available for redistribution 